\title{
oSSIO ACUÑA Juan, Etnografía de la cultura andina
}

\section{Pablo F. Sendón}

\section{(2) OpenEdition Journals}

\section{Edición electrónica}

URL: https://journals.openedition.org/jsa/17626

DOI: 10.4000/jsa. 17626

ISSN: 1957-7842

\section{Editor}

Société des américanistes

\section{Edición impresa}

Fecha de publicación: 20 diciembre 2019

ISSN: 0037-9174

\section{Referencia electrónica}

Pablo F. Sendón, «ossı acuña Juan, Etnografía de la cultura andina», Journal de la Société des américanistes [En línea], 105-2 | 2019, Publicado el 20 diciembre 2019, consultado el 03 septiembre 2022. URL: http://journals.openedition.org/jsa/17626 ; DOI: https://doi.org/10.4000/jsa.17626

Este documento fue generado automáticamente el 3 septiembre 2022.

All rights reserved 


\title{
OSSIO ACUÑA Juan, Etnografía de la cultura andina
}

\author{
Pablo F. Sendón
}

\section{REFERENCIA}

OSSIO ACUÑA Juan, Etnografía de la cultura andina, Fondo Editorial del Congreso del Perú, Lima, 2018, 507 p., bibliogr., ill., mapas.

1 El volumen que nos toca reseñar -que hasta donde tenemos noticia ya ha sido objeto de dos comentarios oriundos de su país de origen, uno de ellos lamentable en su pereza, el segundo conmovedor en su genuflexión- es un buen libro. Es más, la mera comparación con publicaciones recientes dedicadas a temáticas similares hace de él incluso un muy buen libro, un libro casi imprescindible.

2 Lejos de tratarse, como se lo presenta, de un compendio de las cinco décadas de carrera docente del autor en la Pontificia Universidad Católica del Perú al frente de la asignatura "Etnología andina" o "Etnografía andina" (p. 17), el volumen es un libro de antropología escrito por un antropólogo que sabe de antropología y que conoce muy bien su materia; pero no se trata de un libro de antropología concebido bajo los preceptos del género etnográfico sino de una reflexión sintética aunque detallada de las investigaciones que el autor dedicó a aquello que José María Arguedas denominó “cultura india” (p. 23), a partir de una perspectiva que busca trascender las constricciones del estudio de caso y de la coyuntura histórica. En este sentido, estamos en presencia de una extensa reflexión repleta de información de base de carácter etnográfico, histórico y etnohistórico- acerca de la "cultura andina" tal y como es concebida y expresada por los indios del Perú o, para ser fieles a la fraseología del autor, de un "paradigma [construido] sobre bases empíricas" de la cultura de las "comunidades campesinas de los valles interandinos" peruanos (p. 27-28). A la vez, el libro está exento del más mínimo coqueteo con pronunciamientos de moda que han venido abordando problemas similares en términos de una "ontología" irreductible al entendimiento y sensibilidad de, digámoslo así, el ethos occidental. No: 
fiel al método científico que la antropología diseñó durante décadas para comprender y explicar los usos y costumbres de diferentes sociedades y culturas del mundo, Juan Ossio lo ha hecho suyo para hacer lo propio en los Andes peruanos. Esto, a su vez, hace que el libro esté exento del chovinismo propio de supuestas "escuelas antropológicas" falsamente fundadas en preceptos nacionales, así como también de la mácula provinciana de otras igualmente atrapadas en los vericuetos regionales impuestos por sus respectivos estudios de caso. De esta manera, el libro está en diálogo con tradiciones antropológicas de otras latitudes, o de buena parte de ellas, no sólo por tratar temáticas afines sino por hablar un idioma común. No debería ser objeto de sorpresa, entonces, que al promediar el volumen el lector se tope con un largo resumen sobre la monarquía divina de los shilluk del Sudán nilótico (p. 262-270) en calidad de introducción a los rituales andinos o fenómenos afines -tales como el mesianismo- de la cual son "expresiones análogas" (p. 261). Junto con estas razones, el libro se encuentra emparentado con una extensa literatura académica dedicada al área andina que hace de él uno de los últimos, sino el último hasta hoy, libro "clásico" de antropología dedicado a las poblaciones indígenas del Perú contemporáneo y sus antepasados -que, junto con ellos, se perfila como un género en peligro de extinción.

De manera concienzuda y pausada, la exposición dedica el primer movimiento a identificar el desarrollo de una "orientación homogeneizadora" (p. 26 passim) que, desde los períodos colonial y republicano -e incluso desde el período incaico, pero con otros bemoles-, ha involucrado la "dominación" de ciertos grupos humanos sobre otros en el contexto de un "proceso colonizador" y por ende a la subsiguiente "exclusión" de los segundos al negárseles el derecho a su propia "identidad cultural" (p.37). Esta orientación, que en la relación alcanzada entre los criollos republicanos y las poblaciones campesinas parece replicar aquella otra generada en el encuentro entre el conquistador español y la masa indígena, ha redundado en un fenómeno en virtud del cual el "sistema social andino", basado en "el parentesco, la reciprocidad y la redistribución" (p. 50), se ha visto replegado al ámbito local, donde continúa funcionando por fuera de la órbita de los sucesivos sistemas estatales que se le han impuesto ${ }^{1}$. Frente a esta masa desconocedora e incluso descalificadora de los usos y costumbres de los indios peruanos, comienza a vislumbrarse, hacia la segunda mitad del siglo xIX -pero como resultado de procesos que la anteceden- una sensibilidad primero social, luego política, más tarde estética y más tarde aún académica que bajo diversas expresiones institucionales supo acuñar el rótulo de "indigenismo", segundo movimiento de la obra. Expuesto en términos seculares, el indigenismo ideologizado y centralista de la primera mitad del siglo xx, estrechamente asociado con los nombres de José Carlos Mariátegui y Luis Eduardo Valcárcel, es introducido y contrastado con la versión liberal y descentralizada del siglo precedente a propósito de la figura de Juan Bustamante Dueñas, la organización que supo fundar (la "Sociedad Amiga de los Indios") y su rol cuasi quijotesco en una insurrección emblemática de la segunda mitad del siglo xix: el levantamiento indio de Huancané en Puno. El indigenismo y muchos de sus exponentes estuvieron cerca -algunos de ellos fueron incluso protagonistas- de un complejo proceso jurídico, institucional y político con consecuencias profundas para el segundo siglo de la historia republicana del Perú: el reconocimiento del "indio" -luego devenido "campesino"- como ciudadano con derechos en el ámbito nacional en virtud de su pertenencia a una unidad sociológica denominada "comunidad campesina". Es preciso admitir que este último término aparece en el libro con numerosas variaciones no exentas de matices y problemas: "comunidades campesinas de los valles interandinos" (p. 27), "comunidades campesinas 
indígenas" (p. 103), "comunidades campesinas contemporáneas" (p. 103) o "comunidades indígenas" (p. 119). En todo caso, basta con señalar que el tercer movimiento de la obra se dedica a describir la formación e institucionalización de este tipo de "unidad social" (p.128) cuyo número, de acuerdo con información censal del presente siglo, asciende a más de 6000. Desde una perspectiva que busca entender las formas de organización social de estas poblaciones, este capítulo es el más importante pues expone algunos de los hitos institucionales en la legislación de este tipo de organización, así como algunos de los criterios de los propios comuneros para acceder a ella: principalmente el ejercicio de adecuar o redefinir las unidades sociológicas vernáculas menos inclusivas al nivel del "distrito" a la cartografía política propuesta por el damero estatal. Pero lo verdaderamente importante aquí es que expone de forma detenida la tesis principal que anima la obra: las "comunidades campesinas" en el Perú contemporáneo son "las unidades sociales más representativas y numerosas de las poblaciones indígenas andinas [que] tienen la virtud de actuar como fuentes recreadoras de su cohesión social y sus tradiciones culturales" (p. 103). Por su parte, "las bases que le dan continuidad a la cultura andina" (p. 137) son tres: los lazos de parentesco, matrimonio y compadrazgo que mantienen entre sí los miembros de la población indígena nucleados en comunidades. Cada una de estas bases es objeto de tratamiento pormenorizado en los siguientes tres movimientos de la obra. En el plano de la consanguinidad, se destaca la significativa orientación endogámica y el lugar que ocupa en estas poblaciones la forma de organización conocida bajo el término ayllu. Por su parte, las regulaciones matrimoniales son de carácter "proscriptivo" en lugar de "prescriptivo", y sus características "positivas", deducibles estadísticamente, están ligadas con la orientación endogámica indispensable para la reproducción del orden social y cultural. El parentesco ceremonial, y en particular el vínculo de compadrazgo resultado de la celebración del matrimonio religioso, presenta una dimensión doble (individual y colectiva) cuyos "rasgos estructurales" (p. 243) son reflejo del carácter bilateral y ego-centrado del sistema, de la terminología de parentesco y de la tendencia simétrica y endogámica de la alianza matrimonial -rasgos que, en su conjunto, parecen encontrar ecos en el pasado precolombino (p. 253).

4 Los últimos cuatro movimientos se consagran a exponer y discutir las fiestas cívicoreligiosas, el mesianismo, el orden económico y las relaciones interétnicas andinas. Los rituales consagrados a los santos patrones -devenidos "clasificadores totémicos" (p. 271) que supieron reemplazar a las antiguas divinidades prehispánicas- constituyen mecanismos para "recrear la unidad [y la cohesión social] de los conglomerados más amplios a los cuales están adscritos" (p. 261). Así como "las comunidades [...] devinieron las unidades sociales más representativas de las poblaciones indígenas después de la Conquista" (p. 273), se condensó en la figura de sus respectivos patrones las respectivas totalidades de los conjuntos sociales, cuyas respectivas configuraciones simbólicas remiten a aquello "que en antropología se conoce como organización dualista" (p. 274), encargada de recrear en última instancia la unidad en cuestión. Junto a uno de sus componentes, el monarca divino que lo anima "fusionado" (p. 352) a la figura del "Inca", este modelo guarda estrecha correspondencia con la obra de Felipe Guaman Poma de Ayala, entendida como un "ruego de naturaleza mesiánica al rey de España para retornar al orden" (p. 352) perdido. La lógica que inspira este ruego de orden "metafísico" (p. 358) se aprecia en otros ejemplos afines de mesianismo andino tales como los levantamientos de Juan Santos Atahualpa y José Gabriel Condorcanqui, el mito de Inkarrí o bien el movimiento contemporáneo encabezado por el profético Ezequiel Ataucusi Gamonal: la 
Asociación Evangélica de la Misión Israelita del Nuevo Pacto Universal. El orden económico, por su parte, parece garantizarse por el papel protagónico de la comunidad en la toma de decisiones referida a la tenencia, usufructo y propiedad de la tierra, sujeta esta última a una dialéctica incesante de concentración y dispersión que se resuelve de manera equilibrada a través del juego recíproco entre los diversos mecanismos que posibilitan su circulación, dispersión y concentración: el parentesco, el matrimonio y las relaciones de compadrazgo. Cierra el volumen una reflexión en torno de las relaciones interétnicas en los Andes peruanos, en la que se propone "la existencia de una unidad andina que reposaría en una matriz sociocultural de origen prehispánico" (p.468), garantizada a lo largo del tiempo por las "políticas tributarias" de los períodos inca y colonial, y luego las "leyes proteccionistas" republicanas que promovieron el "reconocimiento legal" de las comunidades campesinas que devinieron cada vez más "corporativas", "localistas" y "alejadas" del conjunto nacional (p. 465-466).

Estamos ante un todo coherente, macerado, bien pensado en todas sus articulaciones; un "paradigma", como se prometió al comienzo de la obra, o quizás un "tipo ideal", tal como preferimos rotularlo en virtud de la lección de método que promueve: cotejarlo con cuantas instancias empíricas y etnográficas sea posible con miras a hacerlo, en caso de ser necesario, aún más perfectible. Esto mismo es lo que proponemos hacer a continuación a propósito de un fenómeno que el autor toma como hecho consumado pero nos coloca ante una serie de problemas etnográficos, etnohistóricos y antropológicos simultáneos: se trata, en efecto, de la tesis misma del libro.

6 Si las "comunidades campesinas" son las unidades sociales que posibilitan la "recreación de la cohesión social y la tradición cultural" de las "poblaciones indígenas andinas" (p. 103), y si "las bases que dan continuidad a la cultura andina" (p. 137) son las prácticas de parentesco, matrimonio y compadrazgo, las comunidades campesinas son las unidades que aseguran el funcionamiento de las prácticas de parentesco, matrimonio y compadrazgo. Es más: si las "comunidades campesinas" son las "colectividades donde se recrea la cultura andina" (p. 137), y si las "bases que dan continuidad a la cultura andina" son las mismas que "sustentan la integridad de las comunidades campesinas" (p. 185), las prácticas de parentesco, matrimonio y compadrazgo son el sustento de la integridad de las comunidades campesinas. Es precisamente esta identificación conceptual entre "comunidad" y "parentesco" -para resumir en dos palabras los pares de opuestos contrastados- la que encontramos problemática, si no equivocada, debido a las siguientes razones, introducidas mediante una anécdota personal.

7 Hacia el comienzo de mis investigaciones etnográficas en la comunidad campesina de Phinaya (Cuzco), fui invitado a presenciar una asamblea ordinaria en la que participaban los representantes de las 40 familias nucleares que la conforman. Al no estar todavía familiarizado con el establecimiento comunal donde se llevaría a cabo el encuentro, fui conducido hacia el mismo por un hombre del que apenas conservo recuerdo: lo que sí recuerdo, y muy bien, es que cuando este individuo abrió la puerta del recinto tuvo un gesto dubitativo a propósito de la mirada inquisidora de un segundo sujeto que, ubicado detrás de un precario escritorio, lo interpeló diciéndole que yo era bienvenido pero que no lo era él, debido a que no era miembro de la comunidad, y por lo tanto se vio obligado a retirarse. Con el tiempo me enteré de que ambos individuos, mi acompañante y el entonces presidente, no sólo eran miembros de uno de los dos ayllus en que se divide el territorio de Phinaya -y a los que pertenecen el total de 130 familias nucleares que los habitan-, sino que también eran hermanos. 
Esta anécdota plantea un problema inmediato a la ecuación "parentesco = comunidad", si no es que la invalida de cuajo: dos hermanos miembros de un mismo ayllu no pueden coincidir en una asamblea comunal, puesto que uno de ellos no pertenece a la misma. Es posible profundizar el dato a propósito de una segunda dificultad que encontramos en un aspecto derivado de la tesis de Ossio: el postulado de que "las comunidades campesinas hunden sus raíces en las concentraciones de indígenas llamadas 'reducciones' que el virrey Francisco de Toledo implementó durante su gobierno (1569-1581)” (p. 103)3.

Nuestro autor ilustra el punto con dos ejemplos. El primero corresponde al repartimiento ${ }^{4}$ de los rucanas antamarcas (Ayacucho), cuyo territorio, antes de ser sometido a la política toledana, estuvo dividido en cuatro ayllus -de los que no se cuentan con "mayores descripciones" (p. 104) pero de los que se sabe que el principal, "Antamarca", dio nombre al repartimiento-, y en el que se ubicaron 15 reducciones que dieron origen "a las comunidades que se conservan hasta nuestros días" (p. 104). La prueba consiste en la coincidencia (8 en rigor) de algunos de los nombres de estas reducciones consignados en una lista de fines del siglo XVI con los topónimos registrados en un mapa contemporáneo. Esta coincidencia parcial vuelve a corroborarse en el segundo ejemplo. En efecto, otra fuente de fines del siglo xvı registra los nombres de las 39 reducciones -distribuidas en 5 repartimientos- a las que fueron sometidos los más de 200 pequeños pueblos de indios de la antigua provincia de Yauyos (sierra de Lima). Una vez más, 28 de las comunidades registradas para las provincias de Huarochirí y Yauyos en un censo agropecuario de 1972 llevan aún los nombres de las antiguas reducciones. El problema aquí es que el total de comunidades registradas en el censo asciende a 86, hecho que Ossio atribuye a que "las comunidades de esta región estuvieron expuestas a más cambios que las de la zona de los rucanas antamarcas" (p. 109). A diferencia de lo anotado para estos últimos, en Yauyos los cinco repartimientos consignados en la fuente no remiten a una organización social de carácter prehispánico. Una aproximación a este tipo de organización involucraría, según Ossio, "partir de los ayllus [prehispánicos] que fueron reducidos" (p. 113), los que no serían otros que aquellos pequeños pueblos de la antigua provincia cuyos nombres, si bien no están replicados en las 39 reducciones creadas a fines del siglo XVI, encuentran ecos en registros etnográficos y etnohistóricos del siglo xx. La conclusión de Ossio es categórica: "Hacer reconstrucciones históricas de esta naturaleza para las comunidades andinas contemporáneas ayudaría a determinar con mayor exactitud su grado de vinculación con el pasado prehispánico y, por ende, su cercanía a una condición de indianidad que ha venido siendo sistemáticamente negada por la orientación homogeneizadora" (p. 114 -subrayado en el original).

Aunque no debería ser objeto de sorpresa la perdurabilidad a lo largo de siglos de determinados topónimos en espacios relativamente circunscriptos y hasta no hace mucho tiempo de difícil acceso, lo cierto es que el hecho de que la prueba principal de que las comunidades campesinas contemporáneas hundan sus raíces en las reducciones del siglo xvi sea una mera coincidencia de nombres nos parece algo endeble. Unidades sociales que comparten un mismo nombre no tienen por qué ser las mismas. Así, para continuar con nuestro ejemplo, el término "Phinaya" designa una "comunidad campesina", a uno de los ocho "sectores" en los que está dividida y al "centro poblado menor" que preside, y que incorpora a otras cuatro comunidades de la región. La homonimia, sin embargo, es el menor de los problemas. La inflación de comunidades sobre reducciones ${ }^{5}$ a lo largo del siglo xx remite de inmediato al aumento de un tipo de unidades sociales ("comunidades") que no encuentran correspondencia -al menos en 
términos de nomenclaturas o toponimias- con aquellas otras de las cuales se predica su ascendencia ("reducciones") 6 . Esto podría relacionarse con el hecho de que los nombres de las comunidades no registrados en las reducciones del siglo xvi podrían remitir a unidades sociales -o subunidades- no consignadas en las fuentes oficiales, tales como los pequeños 200 ayllus de los yauyos a los que ya se hizo referencia. Aunque algo alambicado, el argumento sigue siendo plausible, pero nos enfrenta a dos nuevos problemas: por un lado, muchos de los nombres de las comunidades del siglo xx no se repiten en los nombres de unidades sociales registradas en las provincias y repartimientos donde se instalaron las reducciones -ni tampoco en sus toponimias-; por el otro, desde esta última perspectiva las raíces de las comunidades contemporáneas parecerían atravesar el suelo de las reducciones coloniales hasta tocar las profundidades de los ayllus prehispánicos. Adicionalmente, así planteado, toda esta discusión omite un problema nuclear: el reconocimiento legal de comunidades al comienzo de la segunda década del siglo xx. Rápidamente diremos que la falta de repetición entre los nombres de unidades sociales contemporáneas (comunidades) y pretéritas (reducciones) no necesariamente obedece a una pendiente identificación de eventuales especímenes de las segundas que ayuden a confirmar la ecuación, sino simplemente a que los primeros fueron introducidos tardíamente en los escenarios locales; asimismo, es imposible que los ayllus prehispánicos sean las bases de las comunidades contemporáneas puesto que, en cualesquiera de sus circunstancias históricas, los primeros remiten a realidades sociológicas inconmensurables con las segundas; y esto es así porque, lejos de que las comunidades del siglo xx supongan el "reconocimiento" legal de realidades sociológicas pretéritas que fueron desatendidas durante la primera centuria de la historia republicana, fueron más bien "creaciones" que se impusieron sobre ellas, no sin ignorarlas, mutilarlas e incluso anularlas. Ilustraremos estos puntos con parte de la casuística procedente de la región donde realizamos nuestras propias investigaciones.

11 Hasta donde conocemos, la mayoría de las poblaciones rurales que habitan el macizo del Ausangate están organizadas en comunidades campesinas y ayllus. Mientras que las primeras son resultado de un proceso de incorporación y ordenamiento de las poblaciones "indígenas" (y luego "campesinas" con la reforma agraria de 1969) en el marco de los límites del territorio nacional, los segundos remiten a unidades sociales de otro orden que aparecen sistemáticamente consignadas en fuentes censales disponibles desde al menos fines del siglo XVIII. El estudio de este tipo de fuentes nos coloca ante el siguiente hecho significativo: mientras que desde la década de 1780 y hasta fines del siglo XIx las unidades mínimas que conformaban los repartimientos eran consignadas como "ayllus", hacia comienzos del siglo xx las mismas comienzan a ser reemplazadas por esas pequeñas repúblicas creadas por el Estado, refrendadas en constituciones y administradas por un ejército de presidentes, vicepresidentes, secretarios, tesoreros, fiscales, jueces de paz y comisiones: las "comunidades". Los nombres de muchas de estas comunidades no tienen correlato con el de los ayllus registrados para la región durante siglo xIX. Así, por ejemplo, el nombre de la comunidad de Phinaya del actual distrito Pitumarca (Canchis) no está registrado en ninguno de los ayllus del ex repartimiento homónimo; y lo mismo ocurre con cuatro de las ocho comunidades del actual distrito de Marcapata (Quispicanchi): Yanacocha-Inca Cancha, Socapata, Unión Arasa y Huaracone. Todos estos nombres están asociados con "comunidades indígenas" que, en calidad de tales, comienzan a ser registradas censalmente a comienzos del siglo pasado. Ahora bien, la encuesta etnográfica nos revela un hecho no menos significativo en términos 
sincrónicos: ellas están también organizadas en ayllus. Así, por ejemplo, el pueblo de Phinaya está dividido en dos ayllus y el distrito de Marcapta en cuatro, y todos ellos encuentran réplica desde fines del siglo xviII en los nombres de dos y cuatro de los ayllus de, respectivamente, los ex repartimientos de Pitumarca y Marcapata. Los nombres de estos seis ayllus son también los de seis de las comunidades campesinas de la región, del tipo que Ossio asocia con aquellas que fueron reducidas en torno de las cabezas de reducción -hoy capitales de distrito- de sus respectivos repartimientos: Consachapi e Ilave en Pitumarca (junto con otras dos que también figuran como ayllus a lo largo del siglo xix: Pampachiri y Capacchapi) y Collana, Sahuancay, Puiqa y Collasuyu en Marcapata. Esta serie de constataciones no está muy alejada del planteo general de Ossio -de hecho, no puede estarlo tratándose de fenómenos de la misma naturaleza-, pero observándola más de cerca no hace sino invertirlo.

Hacia fines del siglo XIX, antes de ser reconocido como "comunidad", el pueblo de Phinaya era un anexo del ayllu Ilave del pueblo de Pitumarca dividido en las mitades mencionadas; y cada una de las primeras cuatro comunidades marcapateñas referidas, antes de ser reconocidas como tales, eran parte asimismo de cada uno de los cuatro ayllus en los que a su vez se dividía el repartimiento. Más allá de los motivos específicos que propiciaron la fragmentación jurídica de estas unidades -y más allá también de la incidencia que un sentido de pertenencia comunitario pueda imprimir en la realidad sociológica de la región-, lo cierto es que actualmente todas ellas continúan funcionando como ayllus e incluso, observándolas desde la perspectiva de estos últimos, parecerían aglutinar lo que desde la perspectiva de la comunidad aparece como separado o desunido. En este sentido, las ocho comunidades campesinas del distrito de Marcapata se traducen en cuatro ayllus del mismo modo en que los ocho sectores (comuneros y privados) del territorio de Phinaya lo hacen en dos, a los que pertenecen todas las familias que los componen. $Y$ es aquí a dónde queríamos llegar para poner a prueba la tesis del libro: si las poblaciones rurales contemporáneas del Ausangate están organizadas en ayllus, y si los nombres de estos ayllus coinciden mayormente con el de aquellos otros ayllus que durante el largo siglo xIX conformaban los repartimientos de la región, ¿no sería más probable que esos primeros ayllus sean los que "hundan sus raíces" en los segundos en lugar de hacerlo las comunidades contemporáneas? No sólo creemos que éste es el caso sino que, además, buena parte de los resultados del análisis genealógico que hemos dedicado a las familias de los ayllus contemporáneos verifican que provienen de aquellos otros ayllus registrados en los censos del siglo XIX, permitiendo de este modo advertir la continuidad de estos últimos en los primeros ${ }^{7}$. En otras palabras, los ayllus de fines del siglo xviII y los ayllus contemporáneos no son dos entidades inconmensurables; en uno y otro caso estamos en presencia de una misma forma de organización social que ha perdurado en el tiempo. Pero esta perdurabilidad se basa menos en una reconstrucción histórica -como la recomendada por Ossio a fin de tender puentes con el pasado prehispánico- que en la constatación etnográfica -y genealógica- de una suerte de bisagra: un tipo de organización social (el ayllu) que, sin dejar de nutrirse en el pasado, no necesita servirse de él -al menos no en términos historiográficos- para exhibir sus atributos contemporáneos. En resumen, mientras que Ossio propone una suerte de "evolución" en lo que respecta a las formas de organización social de las poblaciones indígenas del Perú contemporáneo -de los ayllus a las reducciones, y de estas últimas a las comunidades-, la casuística del Ausangate nos 
coloca ante un fenómeno alternativo: la existencia del ayllu como forma de organización social característica de las poblaciones de la región ${ }^{8}$.

Esta inversión es consecuencia de otra, más profunda y de orden conceptual. Tal y como ha sido formulada, la tesis del libro adolece de un problema generalizado en la antropología de los Andes peruanos: el empleo indistinto de los conceptos de "comunidad", "ayllu", "pueblo" y "andino". En rigor, estos términos corresponden a órdenes de cosas o niveles de análisis distintos: instituciones, patrones de organización social, puntos geográficos y expresiones culturales que pueden coexistir e incluso solaparse pero que no se reducen necesariamente entre si ${ }^{9}$. En el transcurso de tres páginas, Ossio presenta a "Andamarca" como un "distrito", una "comunidad", un "pueblo" y un "pueblo matriz" que, en calidad de tal, "constituye la expresión más tangible y permanente de la organización dualista con que, fieles a la tradición andina, sus moradores organizan el espacio, el tiempo y las relaciones sociales" (p. 286). Desde la realidad etnográfica del Ausangate, nosotros más bien diríamos que, planteado en estos términos, el conjunto de las provincias que compone la región está dividido en una serie de distritos administrados desde sus respectivas capitales distritales -eventualmente nacidas en el proceso reduccional-, cuyos respectivos territorios están compuestos por un número variable de comunidades y de ayllus, siendo las primeras reconocidas y los segundas ignorados por el Estado. Coexistiendo en un territorio común, todos estos elementos son los que conforman un pueblo. Aquellas características que Ossio predica del "pueblo matriz" -las "bases" de la cultura andina"- nosotros las encontramos al nivel de los ayllus; es más, las creemos sus características constitutivas. Si en Andamarca ello no ocurre, quizás sea porque el ayllu como forma de organización social ha dejado de existir allí, como parece haber sido el caso con los dos tipos de ayllu que Ossio identifica en la época contemporánea: "localizados" y "no localizados" ${ }^{10}$. Sin embargo, el asunto se torna más complejo puesto que en Andamarca se conservan "vestigios" (p. 176) de este tipo de organización, al tiempo que también "se reconoce una colectividad de base bilateral que recibe el nombre de ayllu" (p.176), cuyo sentido más restringido se asocia con un "grupo de parentesco ego-centrado, grupo cognático o parentela" (ibid.). Aquí comenzamos a entrar en terreno resbaladizo. ¿Resulta ahora que el ayllu sí existe en Andamarca y que allí el término "ayllu" es sinónimo de parentesco? Sí, y ello es así porque no podría ser de otra forma. El problema reside en otra parte, que no es sino la otra cara de la moneda de la crítica que venimos realizando hasta aquí.

La discusión que nuestro autor propone sobre el ayllu es simétrica, pero inversa, a la desplegada en relación con la comunidad -y a la vez conducente al mismo resultado. En este caso partimos de modelos concebidos por el análisis antropológico acerca de la sociedad incaica antes de la conquista basados, a su vez, en modelos descubiertos en fuentes tempranas; estos modelos se elevan al estatus de "paradigma" y, a partir de ellos, se constata la perdurabilidad de algunas de sus premisas:

ayllupanacacaru aylluaylluayllu

15 Vemos entonces que el ayllu es una agrupación social prehispánica paradigmática basada en el parentesco. Asimismo, el término "ayllu" se empleó también en el pasado para designar un asentamiento en un mismo espacio jurisdiccional, como es el caso de una comunidad. En este sentido, el ayllu es expresión de "diferentes modalidades de agrupaciones sociales" (p.157). Ahora bien, en la actualidad, y como resultado de la coexistencia dispar e incluso contradictoria de algunas o de todas las premisas referidas, 
"la mayor parte de estas [agrupaciones], a excepción de la misma comunidad, [aparecen] luciendo límites no muy definidos" (p. 185).

Desde la perspectiva que ofrece la casuística del Ausangate, la sintomatología es la misma, pero el diagnóstico es inverso. Aquí el ayllu no es sino una agrupación social basada en las relaciones de parentesco (descendencia y alianza matrimonial) entre sus miembros constitutivos ${ }^{11}$. Ahora bien, en el ayllu se conjugan una serie de principios o premisas discrepantes e incluso contradictorias entre sí que, en lugar de presentarse como retazos de eventuales agrupaciones sociales prístinas, dan cuenta más bien de su plasticidad y complejidad contemporánea y cuestionan seriamente, de este modo, la eficacia exegética de los modelos antropológicos diseñados para desentrañar sus misterios. Esto no significa que el ayllu sea expresión de diversas modalidades de agrupaciones sociales ni que, en virtud de ello, sus límites sean poco precisos. No: lo que esto significa es que el ayllu, en su complejidad interna, no puede reducirse a uno $u$ otro de los modelos más o menos formales que fueron diseñados para explicarlo -sobre todo en su versión prehispánica-, ni que la falta de definición de sus límites surja del contraste con otras agrupaciones como la "comunidad". Para expresarlo en términos positivos, el ayllu en la región del Ausangate es expresión de un tipo de organización social en el que se conjuga las bases que promueven la continuidad de la cultura andina -para emplear la fraseología de Ossio-, mientras que la comunidad no necesariamente promueve el reconocimiento de la cultura en cuestión ni descansa sobre las bases que la sustentan. Ello explica por qué dos hermanos que habitan un mismo pueblo pueden pertenecer a un mismo ayllu pero no así a una misma comunidad, tal como sucedía en la anécdota inicial de Phinaya.

Para concluir, esta serie de contrastes apuntan directamente a un aspecto central de la obra que también es de orden conceptual, e incluso teórico: el sesgo teleológico que la anima, y que se traduce en el postulado de la existencia y la perdurabilidad a través del tiempo de una "unidad andina" que reposa sobre una "matriz sociocultural de origen prehispánico". Tal y como lo entendemos, el problema no radica tanto en la imposibilidad de identificar, en el presente o en el pasado, denominadores comunes a partir de los cuales establecer generalizaciones de calibre diverso con miras a promover la añorada unidad como, por el contrario, en que la matriz desde la cual se la concibe termina siendo, en lugar de un paradigma plausible de contrastación, una invención ${ }^{12}$ en la que, a lo largo de todas sus transformaciones, la identidad de un único modelo resulta inconfundible.

Un párrafo aparte merece un último aspecto del libro de Ossio sobre el que no quisiéramos dejar de pronunciarnos en relación con una segunda cuestión de método. Se trata de los pronunciamientos sobre el futuro de los campesinos indígenas del Perú contemporáneo ante la avasalladora "orientación homogeneizadora". El esfuerzo de "destacar [las] peculiaridades que conservan los campesinos indígenas, que los vincula con el período prehispánico" (p. 57) no significa negar la existencia del cambio, sino la posibilidad de promover una cuota de realismo e insistir en que, ignorándolas, "difícilmente se les podrá ayudar para que accedan a los instrumentos que les permitirán marchar al ritmo de la globalización" (ibid.). Y esto es así porque los campesinos fueron privados "de su derecho a ser diferentes. Es decir, de su derecho a decidir sobre su propio desarrollo y a gozar de una cierta autonomía, ya que aunque diferentes, también tienen discernimiento, raciocinio y capacidad para dialogar" (p.58); o, en otras palabras, "no por ser diferentes [tienen] menos capacidad racional o creativa que aquellos sectores 
poblacionales forjados en la cultura occidental o que han accedido a las tendencias modernas" (p. 59). Ahora bien, reconocer "que los pueblos indígenas tienen el mismo potencial que otros seres humanos no quiere decir que se admita que disponen de los mismos instrumentos y conocimientos que aquellos que marchan al ritmo de la historia y de las reglas de juego que viene imponiendo la globalización" (ibid.). Para ello resulta imperioso volver a propiciar al diálogo intercultural con miras a "generar una educación adecuada que permita abrir los horizontes de los pueblos que secularmente han vivido enclaustrados, a fin de que entiendan los requerimientos del mundo moderno y de que su creatividad encuentre cauces más apropiados para las actuales circunstancias" (ibid.). En última instancia, "mientras que el aislamiento [los] prive de poder comprender el comportamiento de los otros, el capitalismo por sí solo no será la única fuente de sus problemas, sino la falta de educación, que les impedirá manejar, como otros, las premisas en las que se funda dicho sistema económico y, en general, la economía de mercado" (p. 63). Para salir de este estado de cosas, Ossio tiene dos ideas en mente: el acceso a la educación formal y el fomento de las industrias extractivas: "siendo la educación el principal medio para alcanzar la modernidad, ella debe impartirse tratando de adecuarse a la realidad cultural de estos pueblos" (p. 447); mientras que "con una buena dosis de responsabilidad, las industrias extractivas pueden constituirse en magníficos polos de desarrollo que ayuden, por un lado, a sacar del aislamiento a muchos pueblos que viven sin medios de comunicación y sin servicios públicos y, por otro, a reafirmar las premisas culturales de estos pueblos, dándoles una nueva dimensión al servicio de un desarrollo sostenible" (p. 60).

Dejando de lado cualquier tipo de opinión sobre estos pronunciamientos, se trata de expresiones de un mismo fenómeno en virtud del cual la gimnasia de una ética de la responsabilidad cede terreno a la de una ética de la convicción o, en otros términos, la vocación científica se ve mancillada por la no menos noble, pero ajena al ámbito de la primera, vocación política.

\section{BIBLIOGRAFÍA}

\section{KUPER Adam}

1988 The invention of primitive society. Transformations of an illusion, Routledge, London/New York. osSIO ACUÑA Juan

1992 Parentesco, reciprocidad y jerarquía en los Andes. Una aproximación a la organización social de la comunidad de Andamarca, Fondo Editorial de la Pontificia Universidad Católica del Perú, Lima.

SENDón Pablo F.

2016 Ayllus del Ausangate. Parentesco y organización social en los Andes del sur peruano, Fondo Editorial de la Pontificia Universidad Católica del Perú/Instituto de Estudios Peruanos/Centro de Estudios Regionales Andinos Bartolomé de las Casas, Lima. 
2018 "Ferreira Francisco y Billie Jean Isbell (eds), A return to the village: community ethnographies and the study of Andean culture in retrospective", Journal de la Société des américanistes, 104 (1), p. 308-314.

2018 "Ferreira Francisco y Billie Jean Isbell (eds), A return to the village: community ethnographies and the study of Andean culture in retrospective", Journal de la Société des américanistes, 104 (1), p. 308-314.

SALOMON Frank y Mercedes NIÑO-MURCIA

2011 The lettered Mountain. A Peruvian village's way with writing, Duke University Press, Durham/ London.

\section{NOTAS}

1. Las ciencias sociales desempeñaron en el Perú un papel protagónico en la consolidación de este tipo de orientación, particular más no exclusivamente aquellas de sesgo de izquierda en sus variantes "marxista" y "funcionalista" -término empleado varias veces en la obra y que, sin haberse explicitado su sentido, no termina de entenderse del todo-, así como sus respectivos centros de desarrollo institucional, tales como la Universidad Nacional Mayor de San Marcos o el Instituto de Estudios Peruanos (p. 55).

2. Penúltima división político-administrativas en la cual se inserta la "comunidad" desde fines del siglo xIX.

3. Al inicio de la obra, Ossio adelanta este postulado con dos precisiones que haremos explícitas más adelante: "[las] reducciones fueron la base de las comunidades indígenas, hoy llamadas campesinas, cuyo reconocimiento legal [...] se inició a principios del siglo xx" (p. 44).

4. Caracterizados como "unidades sociopolíticas originadas en el sistema de encomiendas [...] que pasarían a formar parte de los corregimientos, los que, a su vez, con el tiempo, darían lugar a las provincias que se integraron en los departamentos" (p. 104).

5. En el caso de los rucanas antamarca casi el doble (15/8) y en el de los yauyos casi el triple (86/28).

6. El autor es consciente de ello, por lo que no puede dejar de admitir, con respecto a los yauyos, que "es muy probable que un estudio de las 58 [comunidades] restantes pueda ayudarnos a identificar las [reducciones] que nos faltan" (p. 109). Sin embargo, al terminar de escribir estas líneas, nos vimos necesariamente obligados a cotejar el ejemplo de los rucanas antamarcas con el análisis que el propio Ossio les dedicó oportunamente en su investigación sobre la comunidad de Andamarca. Tras examinar lo que entendemos es la misma información de base, entonces concluía lo siguiente: "Esto quiere decir que Andamarca no surge con las reducciones que por 1580 hace el Virrey Toledo" (Ossio Acuña 1992, p. 67).

7. Sendón 2016.

8. Aunque en principio podría pensarse que esta es una característica peculiar de la zona de estudio, ello es dudoso. Refiriéndose brevemente a la organización social de la actual comunidad campesina de San Andrés de Tupicocha en la provincia de Huarochirí coincidente con el segundo ejemplo de Ossio antes citado- Frank Salomon y Mercedes Niño-Murcia sostienen que ella está dividida en una serie de ayllus, que estos ayllus son 
grupos de parentesco, que estos grupos funcionan de manera paralela a la comunidad haciéndolo "por su propia voluntad, ya que el Estado reconoce a la comunidad como un todo y no tiene ningún interés en su segmentación interna" (2011, p. 62 -nuestra traducción).

9. Nos hemos referido específicamente a este problema en la última reseña que publicamos en este medio (Sendón 2018).

10. "En Andamarca, este tipo de ayllu ha desaparecido. Desafortunadamente, ignoramos cuándo sucedió y las circunstancias que influyeron en ello (p. 171).

11. Lo que no quiere decir que no se exprese asimismo en otros órdenes de cosas.

12. En el sentido específico otorgado por Adam Kuper (1988) al término.

\section{AUTORES}

\section{PABLO F. SENDÓN}

Conicet, Argentina 